\title{
Is extinction of fear erasure or inhibition? Why both, of course
}

\author{
Mark Barad \\ Veterans Health Administration, West Los Angeles, Los Angeles, California 90073, USA; Semel Institute of Neuroscience \\ and Human Behavior, University of California, Los Angeles, California 90095, USA
}

For many decades, classically conditioned fear has provided fertile ground for neuroscientists interested in learning and memory. The paradigms are conceptually straightforward, the protocols robust, and the relevance to the human (and animal) condition unquestionable. Fear, or something very like it, is probably as old as the animal kingdom. One of the great advantages of being an animal, and thus being able to move, is the privilege of avoiding unpleasant experiences. Aversive learning is therefore ancient, and well conserved. The study of conditioned fear in mammals has benefited from this long history, since a large part of the circuitry of fear is old and relatively uncomplicated. The short circuits from senses to amygdala and back out to behavior have allowed neuroscientists to define the anatomy of fear in great detail and to provide a wealth of data that fear conditioning in mammals involves the same strengthening of synapses, and uses many of the same molecular switches to do so, as does the facilitation of the gill withdrawal reflex in Aplysia.

However, fear is a mixed blessing for animals. Fear is protective and absolutely necessary to animal survival. Nevertheless, fear that is indiscriminate displaces many crucial activities of life, like eating, sleeping, and having sex. It is therefore not enough to learn to be afraid of dangerous things; it is just as essential to eliminate fear of the safe ones and to tune fear to the degree of danger. Evolution has yielded numerous mechanisms that winnow the safe aspects of an experience from the dangerous ones. In conditioned fear experiments, the effect of these mechanisms is observed by the reduction they cause in a conditioned fear response.

Pairing of a neutral stimulus (the conditioned stimulus, CS, e.g., a light) with an intrinsically aversive stimulus (the unconditioned stimulus, US, e.g., a footshock) generates conditioned fear of the CS. Behavioral scientists measure this fear in increased heart rate, blood pressure, and other physiological changes, as well as in a number of behavioral responses including freezing and the potentiated startle reflex used by Myers and her colleagues (Myers et al. 2006) as an index of fear in the experiments reported in this issue. A variety of manipulations yield decreased fear of a cue that has been paired with footshock. Forgetting is not one of them; once trained, and without further manipulation, conditioned fear lasts a lifetime, essentially unchanged (Gale et al. 2004). However, a variety of experimental manipulations can reduce the behavioral expression of that fear. The most familiar, and arguably, the best studied, protocol of this kind is extinction.

Repeated presentation of the CS in the absence of the US after conditioning generates extinction of conditioned fear. The result of these repetitions is quite profound, and after enough training, there can be no detectable sign of the original fear. Has it been erased? For a long time the answer has been, "No." A

E-mail mbarad@mednet.ucla.edu; fax (310) 206-5855.

Article and publication are at http://www.learnmem.org/cgi/doi/10.1101/ Im.211306. convincing set of experiments argue that extinction is not erasure of the original fear but, rather, new and independent inhibitory learning. That new learning suppresses the expression of an intact fear memory under certain circumstances, while allowing it to be expressed in other circumstances, perhaps evolutionarily more appropriate ones. The argument for this interpretation depends strongly on three phenomena in which fear returns after extinction without further CS-US pairings. "Reinstatement" refers to the return of fear after a presentation of the US without any paired CS (Rescorla and Heth 1975). Renewal is perhaps the most dramatic of these phenomena. After extinction in one context, animals can be moved to another context and immediately show intact fear of the CS (Bouton and Bolles 1979). "Spontaneous recovery" refers to the return of fear simply with the passage of time after extinction (Baum 1988). Since no further CS-US pairing occurs to retrain the fear association, these phenomena argue that the original association must remain even after extinction. These observations, and others, have made an elegant, and apparently airtight, psychological case for extinction as a learned inhibition of fear, rather than an erasure or forgetting of fear.

Recently, a series of neuroscience experiments has challenged this view, and revived the possibility that extinction is erasure, and not merely inhibition, of an association (Lin et al. 2003a,b,c). These experiments show that some of the changes that occur in the amygdala during extinction oppose the changes in that area during acquisition of fear, and resemble changes associated with depotentiation, the reversal of long-term potentiation of synaptic strength, by low frequency stimulation delivered to the same synapse shortly after the induction of long-term potentiation by high frequency stimulation (Fujii et al. 1991; Bashir and Collingridge 1994). If depotentiation were the mechanism of extinction, then extinction would represent erasure of the original association, at least insofar as that association is represented by strengthening of synapses in the amygdala. However, there is an important reservation: Depotentiation can only be evoked shortly after the establishment of long-term potentiation, within minutes to an hour, and thus it would be hard to posit this mechanism for extinction in general, which can occur days after training, and probably much later than that.

In this issue of Learning \& Memory, Myers and her colleagues (Myers et al. 2006) report an elegant series of experiments in rats that helps resolve this paradox. The experiments suggest that extinction is both inhibitory learning and erasure, depending on the interval between training and extinction. In tests of the three most cited phenomena in which fear returns after extinction: reinstatement, renewal, and spontaneous recovery, they show that extinguished fear does not return in any of those protocols when extinction is performed $10 \mathrm{~min}$ after fear conditioning. Similarly, when extinction training begins within an hour of training, these return of fear phenomena are weak, and only spontaneous recovery yields a significant return of fear. On the other hand, when extinction training begins $72 \mathrm{~h}$ after fear conditioning, rats show large and significant reinstatement, renewal, 
and spontaneous recovery. The report from Myers and her colleagues argues strongly that there are two kinds of extinction. Extinction that begins late after fear conditioning satisfies all the conditions that have been used to argue for extinction as inhibitory learning and not erasure. However, when extinction begins early, within $10 \mathrm{~min}$ of conditioning, it shows no sign of the phenomena used to argue that the original fear remains intact. Thus, when extinction begins shortly after fear conditioning itself, perhaps within the window for depotentiation, it looks very much like erasure of the original association.

Interestingly, this time course very much resembles the time course for the L-type voltage-gated calcium channel (LVGCC) dependence of extinction memory as reported in a recent issue of Learning \& Memory (Cain et al. 2005). The experiments in that article show that LVGCC antagonists block extinction, as long as extinction begins one hour or longer after fear conditioning. However, when extinction training began immediately after conditioning, LVGCC antagonists had no effect. Thus, there is now convergent evidence from two laboratories that the mechanisms of extinction are different depending on when extinction begins.

Cain and his colleagues also tested the effect of LVGCC antagonists on partial reinforcement, a protocol in which CS-US pairings are intermixed with CSs presented alone (Siegel 1977; Singh and Banerji 1986). LVGCC antagonists did not block the effect of such extra CS presentations in reducing fear of the CS. That experiment provides a hint of the difference between early extinction and late extinction, since the partial reinforcement effect can also be thought of as the extreme case of early extinction. Although partial reinforcement, like extinction, has been interpreted as a form of inhibitory learning balanced against the excitatory learning generated by CS-US pairings (Rescorla and Wagner 1972), the experiments of Myers and her colleagues as well as those of Cain and his colleagues argue that partial reinforcement may well be a form of partial erasure, used by animals to represent the magnitude or risk of danger, and not just the existence of danger. Such an estimation of risk, albeit unconscious, could easily be represented in the degree of strengthening in synapses that encode the association. Late extinction may represent instead, as argued by Mark Bouton, a superimposed learning of safety that is strongly dependent on the context (temporal or spatial) in which it occurs (Bouton 2004). Of course, the experiments in Myers et al. may support other interpretations.
However, at the very least, they challenge the classification of many fear reducing phenomena as all examples of inhibitory learning, and suggest a more nuanced approach.

\section{References}

Bashir, Z.I. and Collingridge, G.L. 1994. An investigation of depotentiation of long-term potentiation in the cal region of the hippocampus. Exp. Brain Res. 100: 437-443.

Baum, M. 1988. Spontaneous recovery from the effects of flooding (exposure) in animals. Behav. Res. Ther. 26: 185-186.

Bouton, M.E. 2004. Context and behavioral processes in extinction. Learn. Mem. 11: 485-494.

Bouton, M.E. and Bolles, R.C. 1979. Contextual control of the extinction of conditioned fear. Learn. Motiv. 10: 445-466.

Cain, C.K., Godsil, B.P., Jami, S., and Barad, M. 2005. The L-type calcium channel blocker nifedipine impairs extinction, but not reduced contingency effects, in mice. Learn. Mem. 12: 277-284.

Fujii, S., Saito, K., Miyakawa, H., Ito, K., and Kato, H. 1991. Reversal of long-term potentiation (depotentiation) induced by tetanus stimulation of the input to ca1 neurons of guinea pig hippocampal slices. Brain Res. 555: 112-122.

Gale, G., Anagnostaras, S., Godsil, B., Mitchell, S., Nozawa, T., Sage, J., Wiltgen, B., and Fanselow, M. 2004. Role of the basolateral amygdala in the storage of fear memories across the adult lifetime of rats. J. Neurosci. 24: 3810-3815.

Lin, C.H., Lee, C.C., and Gean, P.W. 2003a. Involvement of a calcineurin cascade in amygdala depotentiation and quenching of fear memory. Mol. Pharmacol. 63: 44-52.

Lin, C.H., Yeh, S.H., Leu, T.H., Chang, W.C., Wang, S.T., and Gean, P.W. 2003b. Identification of calcineurin as a key signal in the extinction of fear memory. J. Neurosci. 23: 1574-1579.

Lin, C.H., Yeh, S.H., Lu, H.Y., and Gean, P.W. 2003c. The similarities and diversities of signal pathways leading to consolidation of conditioning and consolidation of extinction of fear memory. J. Neurosci. 23: 8310-8317.

Myers, K.M., Ressler, K.J., and Davis, M. 2006. Different mechanisms of fear extinction dependent on length of time since fear acquisition. Learn. Mem. (this issue).

Rescorla, R.A. and Heth, C.D. 1975. Reinstatement of fear to an extinguished conditioned stimulus. J. Exp. Psychol. Anim. Behav. Process. 1: 88-96.

Rescorla, R.A. and Wagner, A.R. 1972. A theory of Pavlovian conditioning: Variations in the effectiveness of reinforcement and nonreinforcement. In Classical conditioning II (eds. A.H. Black and W.F. Prokasy), pp. 64-99. Appleton-Century-Crofts, New York.

Siegel, S. 1977. Morphine tolerance acquisition as an associative process. J. Exp. Psychol. Anim. Behav. Process. 3: 1-13.

Singh, M. and Banerji, M. 1986. Interference in conditioning by CS-alone and US-alone trials. Psychol. Stud. (Mysore) 31: 108-112. 


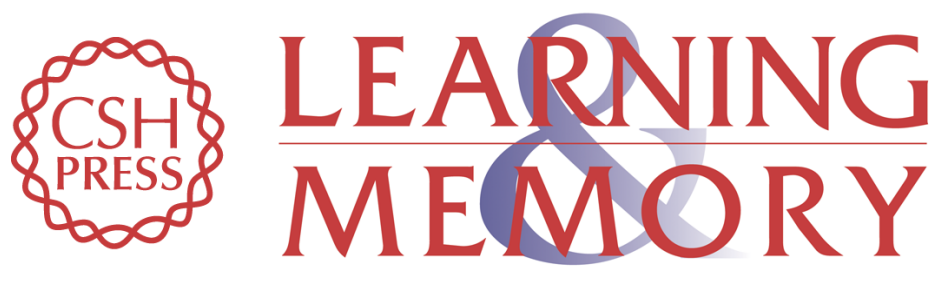

\section{Is extinction of fear erasure or inhibition? Why both, of course}

\section{Mark Barad}

Learn. Mem. 2006, 13:

Access the most recent version at doi:10.1101//m.211306

References This article cites 13 articles, 6 of which can be accessed free at: http://learnmem.cshlp.org/content/13/2/108.full.html\#ref-list-1

License

Email Alerting Receive free email alerts when new articles cite this article - sign up in the box at the Service top right corner of the article or click here. 